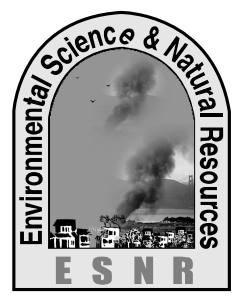

J. Environ. Sci. \& Natural Resources, 5(1): 229-237, 2012

ISSN 1999-7361

\title{
Land Classification for Optimal Use of Land by Remote Sensing and GIS Technology
}

\author{
M. F. Haque ${ }^{1}$, M. S. Ali ${ }^{1}$, M. A. Haq ${ }^{2}$ and M. M. R. Akhand ${ }^{3}$ \\ ${ }^{1}$ Bangladesh Space Research and Remote Sensing Organization (SPARRSO), Dhaka \\ ${ }^{2}$ Ministry of Defence, Government of Bangladesh (GoB) \\ ${ }^{3}$ Bangladesh Space Research and Remote Sensing Organization (SPARRSO), Dhaka
}

\begin{abstract}
In this paper, attempt has been made to prepare landuse map for the district of Brahmanbaria, situated in the east-central part of Bangladesh using remote sensing technique. The multi-spectral Landsat TM data for 3 November 2002, 15 December 2004,01 February 2002, 14 March 2003 and some aerial photographs of December 2000 have been used for land-use mapping for major three crops namely aman rice (late July - early November), winter (rabi) crops and winter (boro) rice. The imagery covers the growing seasons of the above crops, where multi-spectral and multi-temporal signatures for the green vegetations have been shown in spatial domain. The interpretation of the aerial photographs have also been performed and prepared GIS layers containing the water bodies and settlements. All the signature files including the interpretations of aerial photographs have been combined to produce a composite file in GIS layers. These layers were then combined to prepare the landuse maps including the three major crops cultivated round the year. Moreover, the landuse map of Akhaura upazila was compared with the land-type map and a relation of the landuse with the land-type has also been derived. The extracted feature files corresponding to spectral signatures have been overlaid to estimate the distribution of three major crop types in the study area. The result implies that all the three major crops like, aman, rabi and boro were cultivated in the same land which was $9.2 \%$ of total land area. Similarly, areas under double and single crops were also estimated and the result revealed that all the three crop types cover $68.3 \%$ of the total land area of Brahmanbaria district.
\end{abstract}

Key words: GIS, Land use, Remote sensing

\section{Introduction}

Remote sensing is a useful tool for mapping the surface cover types such as land, water and vegetation. The timely accurate agricultural information using remote sensing techniques are of strategic importance for determining the food policy and management of the food crisis in case of crop damage due to disasters like severe drought, flood etc. The monitoring of rice cultivation for a selected area of Bangladesh was performed by Quadir and Nessa (1998) using multidate Landsat TM data, where the crops were identified using Normalized Difference Vegetation Index (NDVI) imagery at different dates. The country wide rice cultivation monitoring and assessment technique for Bangladesh has been developed by Choudhury et al. (1993). In this technique, the NOAA-AVHRR-NDVI imagery with spatial resolution of $1.1 \times 1.1 \mathrm{~km}^{2}$ were used where a correction term was introduced which has been derived by comparison of low resolution AVHRRNDVI with corresponding features as observed in high resolution Landsat TM data.

In this study, en effort has been carried out to prepare agricultural landuse maps for the district of Brahmanbaria using the Landsat TM data of different dates. The major crop types and the landuse pattern were identified and mapped using multi-spectral and multi-date imagery of high spatial resolution distributed over the different cropping seasons. The study also incorporates the land-type map to establish the relation of cropping pattern with land types in a selected area of Brahmanbaria district. The study would be helpful to understand the crop and land-use pattern of the study area and could contribute in planning and land zoning process for optimal landuse.

\section{Methodology}

\section{Study area}

The study area was the district of Brahmanbaria situated in the east-central part of Bangladesh (Fig. 1). The extent of the study area is $1900.61 \mathrm{~km}^{2}$ lying between latitudes $90^{\circ} 43^{\prime} 49.35^{\prime \prime} \mathrm{E} / 24^{\circ} 16^{\prime} 10.56^{\prime \prime} \mathrm{N}$ and longitude $91^{\circ} 18^{\prime} 56.20^{\prime \prime} \mathrm{E} / 23^{\circ} 38^{\prime} 57.24^{\prime \prime} \mathrm{N}$. The River Titas flowing through the middle of the main land from north to south in a zigzag pattern which feeds water for irrigation. The area is characterized by high land, medium high land, medium low land, and low land. The climate of the area is monsoon dominant, the winter is cool and dry and the summer is wet and hot. A comparison of the landuse with the land-types is done for the selected study area within the district named Akhaura upazila. 


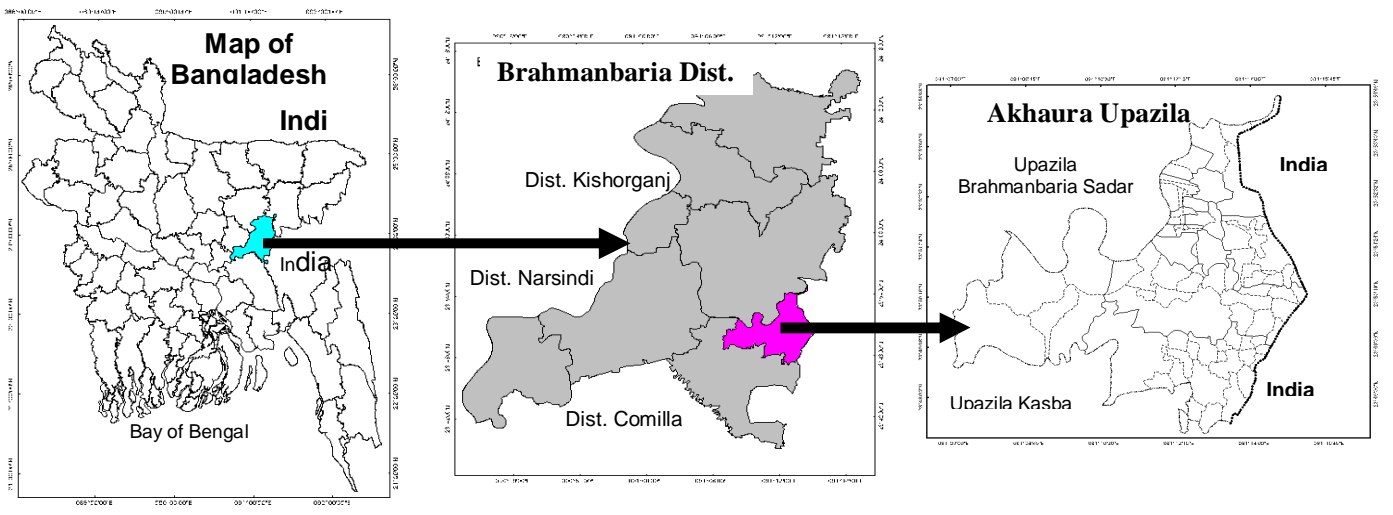

Fig. 1. Location of the study areas within Bangladesh.

\section{Description of the data}

The Landsat TM multi-date data has been used for the study. The imagery was cloud free. The data were obtained from Bangladesh Space Research and Remote Sensing Organization (SPARRSO) archives. The list of data used in the study is shown in Table 1.

Table 1 Table showing the characteristics of Landsat TM and other spatial data

\begin{tabular}{|l|l|c|c|}
\hline Data types & Date & Bands & $\begin{array}{l}\text { Red, Green, Blue (RGB) } \\
\text { color composite }\end{array}$ \\
\hline Landsat TM & 03 Nov. 2002 & $7,5,4,3,2,1$ & $4,3,2$ \\
\hline Landsat TM & 15 Dec. 2004 & $5,4,3$ & $4,5,3$ \\
\hline Landsat TM & 01 Feb. 2002 & $7,5,4,3,2,1$ & $4,3,2$ \\
\hline Landsat TM & 14 Mar. 2003 & $7,5,4,3,2,1$ & $4,3,2$ \\
\hline Aerial & Dec. 2000 & -- & -- \\
\hline Land type map & SRDI, 1996 & -- & - \\
\hline
\end{tabular}

The Landsat data used in this study corresponded different cropping seasons of the year round major agricultural land-use and land-cover, more or less the high vegetative growth stage of aman rice, rabi crops and boro rice. The data of 3 November 2002 accounted for the aman rice. The image of 15 December 2004 represented the rabi crops such as pulse, mustard and wheat. It has to mention that the image consisting of only 3 bands was available for this date at SPARRSO archival. The image of 1 February 2002 showed the wheat in its highest vegetative growth or in the near-maturity stage and the early planted rice, while the image of mid March 2003 represented boro rice crop in its highest vegetative growth stage. Though the imagery belongs to different years but they corresponded to the respective cropping seasons. Only aus rice which was cultivated in the months April - July could not covered because of the non availability of cloud-free imagery during this period.

\section{Methods}

The methodology adapted for this study involved both the digital image processing and GIS based analysis. Landsat images (Fig. 2) were geometrically corrected and geo-referenced with respect to an existing corrected Landsat image. Then the RGB color composites were generated as shown in Table 1 . For land-use classification using temporal remote sensing data, Image Classifier Model (ICM) of ERDAS Imagine software was used. Using the model, spectral signatures from different images over selected Areas of Interest (AOI) have been extracted. The signature files were edited using the signature editor of ERDAS to get reliable spectral signatures of the features of interest. The results of the signatures for the dominant crops for different dates are presented in Fig. 3. Then the different features in the form of raster files were extracted especially for aman, rabi and boro crops using the above spectral signature files and with the help of ICM algorithm (Fig. 4, 5 
and 6). The digital mosaic of aerial photographs was interpreted to delineate the water bodies and settlement areas including the homestead vegetation. The classified layers representing different crops were obtained through the aerial photo interpretations which were then merges for further manipulation and preparation of land-use maps using various combinations of layers representing multiple cropping patterns. The land-use classification of Akhaura upazila has been investigated against the land-types for Akhaura upazila and a qualitative relation between the landuse and land-types has also been derived using visual technique.

\section{Results and Discussion}

\section{Interpretation of $R G B$ composites}

The color composite imagery of the selected dates used in the study is shown in Fig. 2. In these images, the green vegetation is represented as red and water as blue. The light blue and gray indicate bare soil.
The seasonally changing features indicate the seasonal crop rotation, and changes of the inundation levels in the flood plains and flow conditions of the River Titas. In the RGB color composite imagery (Fig. 2) the green vegetation cover is represented by red color because of high reflection in NIR band (Band4) by green leaf and high absorption by leaf chlorophyll in the Red band (Band-3). The image of 03 November 2002 shows the vegetation cover as being red. These were mainly due to rice crops (aman rice), which were planted in the month of late July to early August. This rice had the maximum vegetative growth in October. By November 3, the rice crop gained maturity and began to fade from green to gray. In such a condition, the NIR reflectance decreases and Red reflectance increases causing the difference vegetation index (IR-Red) to become relatively low. At its full mature state, the rice plant turns to gray when the harvesting takes place. In the image of 03 November, the rice coverage was found all over the relatively high lands of the district.
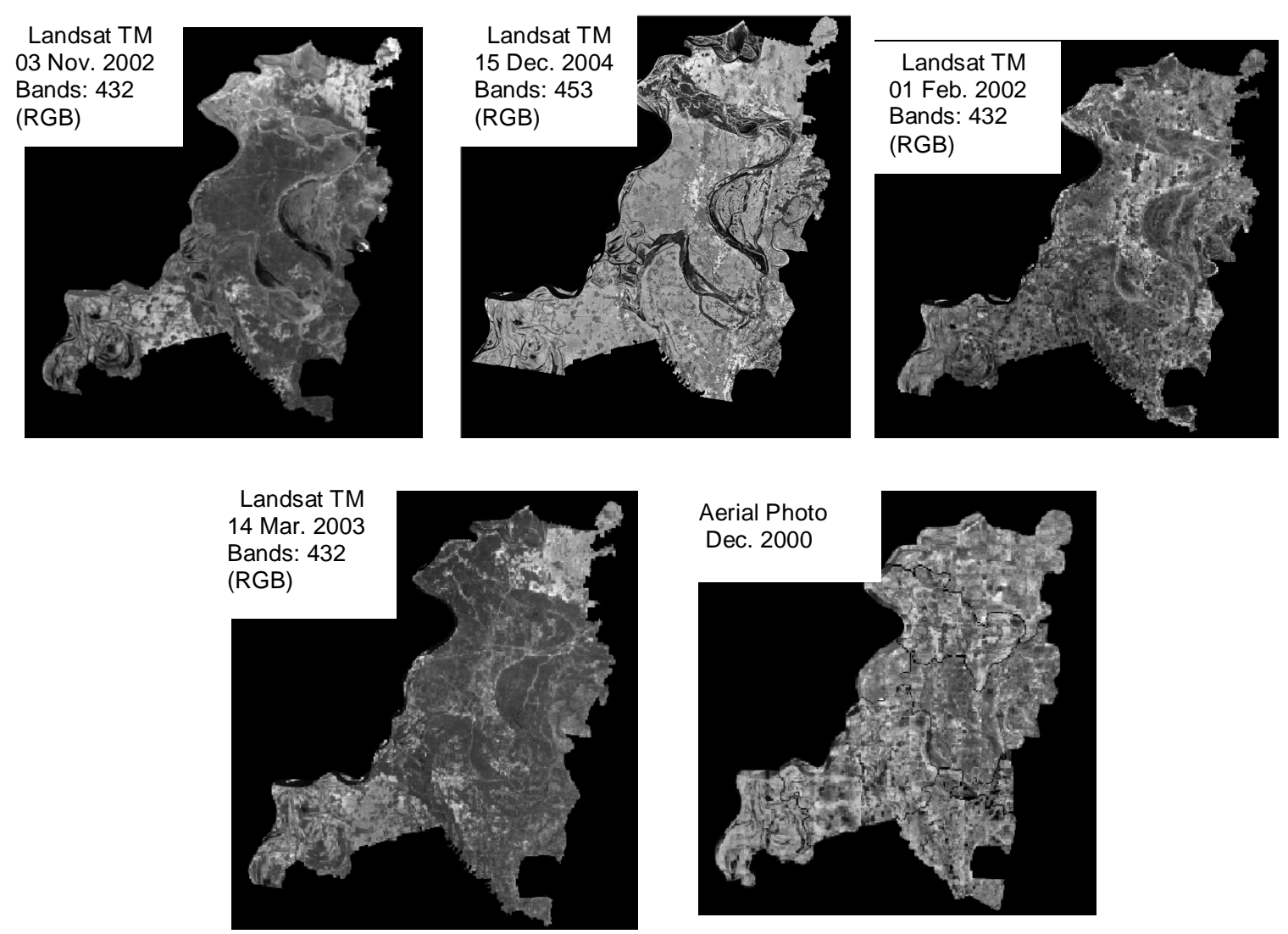

Fig. 2. Color composite Landsat imageries and aerial photograph. 
The RGB composite image of 15 December 2004 using the Landsat TM bands 543 showed very little coverage of green vegetation, because most of the aman rice had been harvested and the remaining rice areas became completely gray and did not show the signature of green vegetation. The blue areas were water over the land areas. It is observed from Fig. 2 that some new areas of green vegetation have appeared in the areas where aman is already cultivated. These were mainly pulse and mustard. Though the wheat cultivation began in mid-December, the signature was very weak because of very low vegetation coverage.

The RGB image of 01 February 2002 using the Landsat TM band combination of 432 showed more areas with signature of green vegetation over these areas. As per the crop calendar, the new vegetations were rabi crops (wheat, pulses and mustard), those were cultivated in December and were already matured and likely to be harvested in early February. In the image of 01 February 2002, some early planted boro rice (planted in January) was supposed to be there. The late planted boro rice were planted in February but was not captured in this image. The lands which had been occupied by pulses and mustard also came under the late boro rice plantation. The vigorous growth of boro rice took place during February to the end of March. Thus the red color areas in the RGB color composite image of 14 March 2003 represented the boro rice crops with considerably high vegetative growth.
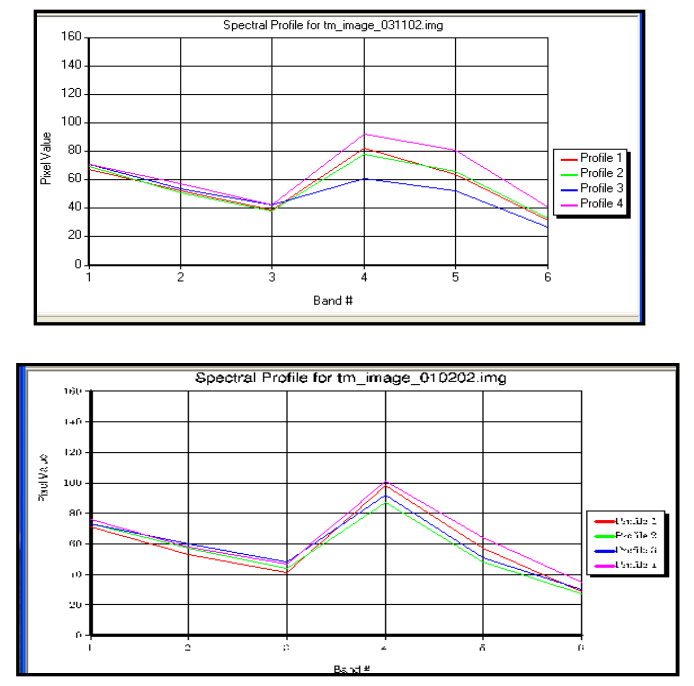

Fig. 3. Spectral signature for vegetation corresponding to 4 selected AOI on each of 4

Landsat imagery used. the spectral signature are shown in Table 2. and still have low coverage of green leaves. to Landsat TM Bands-3,4,5.
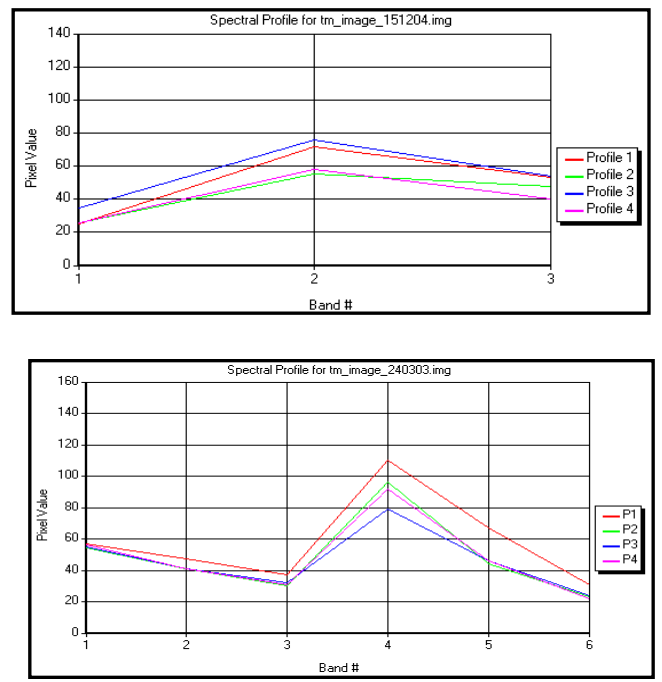

Extraction and interpretation of spectral signatures Having a thorough visual interpretation of the color composite imagery of different dates, another attempt was made to digitally classify the multi-spectral imagery by extracting the spectral signatures of the major landuse features. The AOIs were chosen over the interested features over the RGB imagery of individual dates. The spectral signatures corresponding to the green vegetation in the imagery of different dates are shown in Fig. 3. The values of

From Fig. 3 and Table 2, it has been seen that the difference of the reflectance in Band- 4 and Band- 3 is high for profile 2 and relatively low for profiles 1, 3 , and 4 for the vegetation signatures corresponding to the image of 3 November, 2002. The low response in Band -3 and 4 indicates that the aman rice crops are in the maturing stage and the greenness has faded to some extent. The low reflection in Band-4 for the December image indicates that the aman rice has been harvested and the rabi crops have began to grow

The high response of greenness in the image of 1 February 2002 was due to high concentration of rabi crops and early planted boro rice. The spectral profiles for 14 March 2003 indicate high vegetative growth having high leaf-area coverage, while the other profiles indicate late planted crops having low absorption in Band-3 and low reflection in Band-4 because of relatively lower leaf-area coverage. In Fig. 4 (upper right), the Bands-1,2,3 actually corresponds 


\begin{tabular}{|c|r|r|r|r|}
\hline Bands/1 & AOI-1 & AOI-2 & AOI-3 & AOI-4 \\
\hline 1 & 67 & 69 & 71 & 71 \\
\hline 2 & 52 & 52 & 54 & 58 \\
\hline 3 & 39 & 38 & 42 & 42 \\
\hline 4 & 82 & 78 & 61 & 92 \\
\hline 5 & 64 & 66 & 52 & 83 \\
\hline 6 & 31 & 33 & 27 & 38 \\
\hline
\end{tabular}

Table 2(a). The Landsat TM spectral signatures of vegetation in 4 selected AOI for the November 2002 image

\begin{tabular}{|c|c|c|c|c|}
\hline Bands/3 & AOI- 1 & AOI-2 & AOI- 3 & AOI-4 \\
\hline 1 & 71 & 73 & 73 & 76 \\
\hline 2 & 53 & 53 & 60 & 58 \\
\hline 3 & 41 & 41 & 48 & 47 \\
\hline 4 & 98 & 97 & 92 & 101 \\
\hline 5 & 57 & 58 & 51 & 64 \\
\hline 6 & 29 & 31 & 30 & 35 \\
\hline
\end{tabular}

Table 2(c). The Landsat TM spectral signatures of vegetation in 4 selected AOI for 01 February 2002 image.

\section{Extraction of features}

The parallelepiped decision rules as implemented in ERDAS Imagine software have been used for extraction of the pixels with vegetations based on the

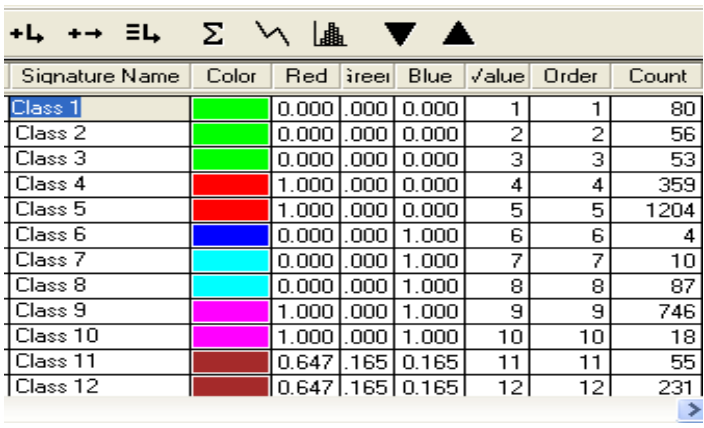

\begin{tabular}{|c|c|c|c|c|}
\hline Bands/2 & AOI-1 & AOI-2 & AOI- 3 & AOI-4 \\
\hline 3 & 25 & 26 & 35 & 26 \\
\hline 4 & 72 & 55 & 76 & 58 \\
\hline 5 & 53 & 48 & 54 & 40 \\
\hline
\end{tabular}

Table 2(b). The Landsat TM spectral signatures of vegetation in 4 selected AOI for the 15 December 2004 image

\begin{tabular}{|c|c|c|c|c|}
\hline Bands/4 & AOI- 1 & AOI-2 & AOI- 3 & AOI-4 \\
\hline 1 & 57 & 54 & 55 & 56 \\
\hline 2 & 47 & 41 & 41 & 41 \\
\hline 3 & 37 & 30 & 32 & 31 \\
\hline 4 & 110 & 96 & 79 & 92 \\
\hline 5 & 67 & 44 & 46 & 46 \\
\hline 6 & 31 & 23 & 24 & 22 \\
\hline
\end{tabular}

Table 2(d). The Landsat TM spectral signatures in 4 selected AOI

For March 2003 image.

spectral signatures. The extracted features corresponding to the signature files automatically contain the attributes, class names, color table, class values and histogram as shown in Fig. 4.

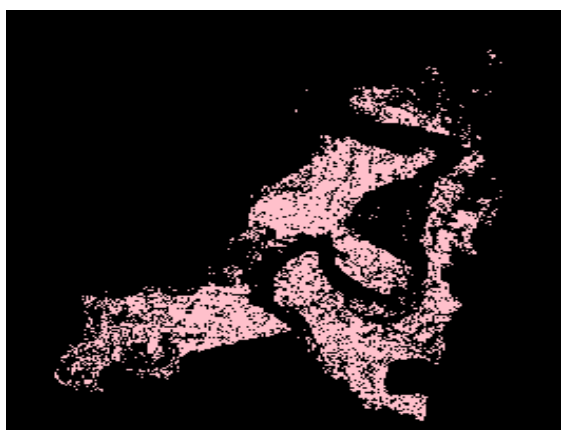

Fig. 4. Extracted vegetation feature for 3 November 2002 image obtained using the corresponding spectral features.

The layers with crop coverage for the imagery of the individual dates as obtained through digital classification technique are shown in Figs. 4 to 6 as thematic images. The features of these layers represent aman crop for 3 November 2002, rabi crops for 15 December 2004, and 01 February 2002 images. These features of December and February have been merged as a single feature class i.e., rabi crops (Fig. 5). The feature extracted from 14 March 2003 is recognized as boro rice and this thematic layer is shown in Fig. 6. All the above features are overlaid in a separate thematic image file. The aerial photographs of the year 2000 was used to identify the water bodies, homestead patterns with perennial vegetation coverage, which helps to digitally delineate land-use features and produce the GIS layers with interpreted themes. These layers were then overlaid with the layers obtained through classification of the Landsat imagery and interpreted in accordance with the spectral signatures. 


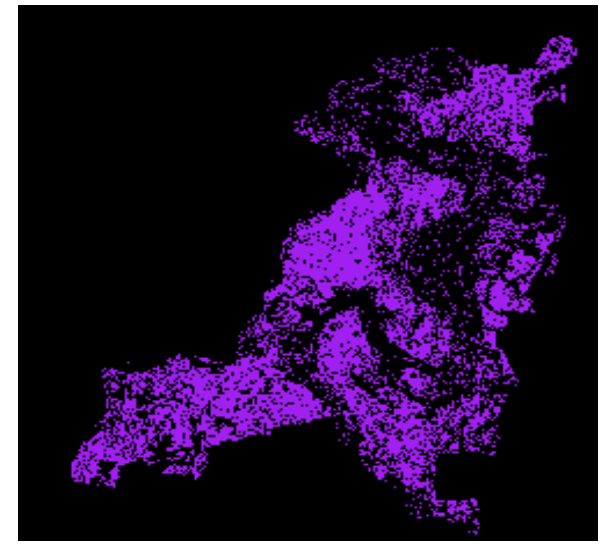

Fig. 5. The extracted features combined for the 15 December 2004 and 1 February 2002 obtained using the spectral signature of vegetation of the respective dates.

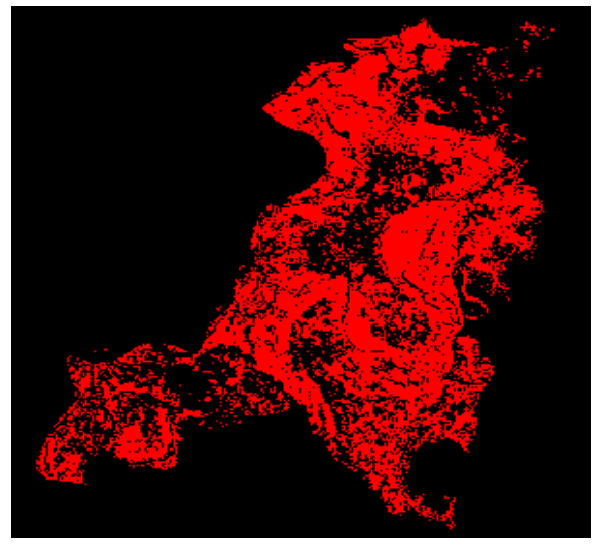

Fig. 6. The extracted features combined images for the 14 March 2003 image obtained using the spectral signature of vegetation

\section{Combination of interpreted layers}

The land-use themes are then manipulated to identify the single, double and multiple cropping patterns (Fig. 7). The upper left figure corresponds to aman and boro $(A+B)$. Similarly, the aman and rabi features are shown in the upper right Fig. The lower left shows the rabi and boro features, and lower right represents aman, rabi and boro $(\mathrm{A}+\mathrm{R}+\mathrm{B})$.
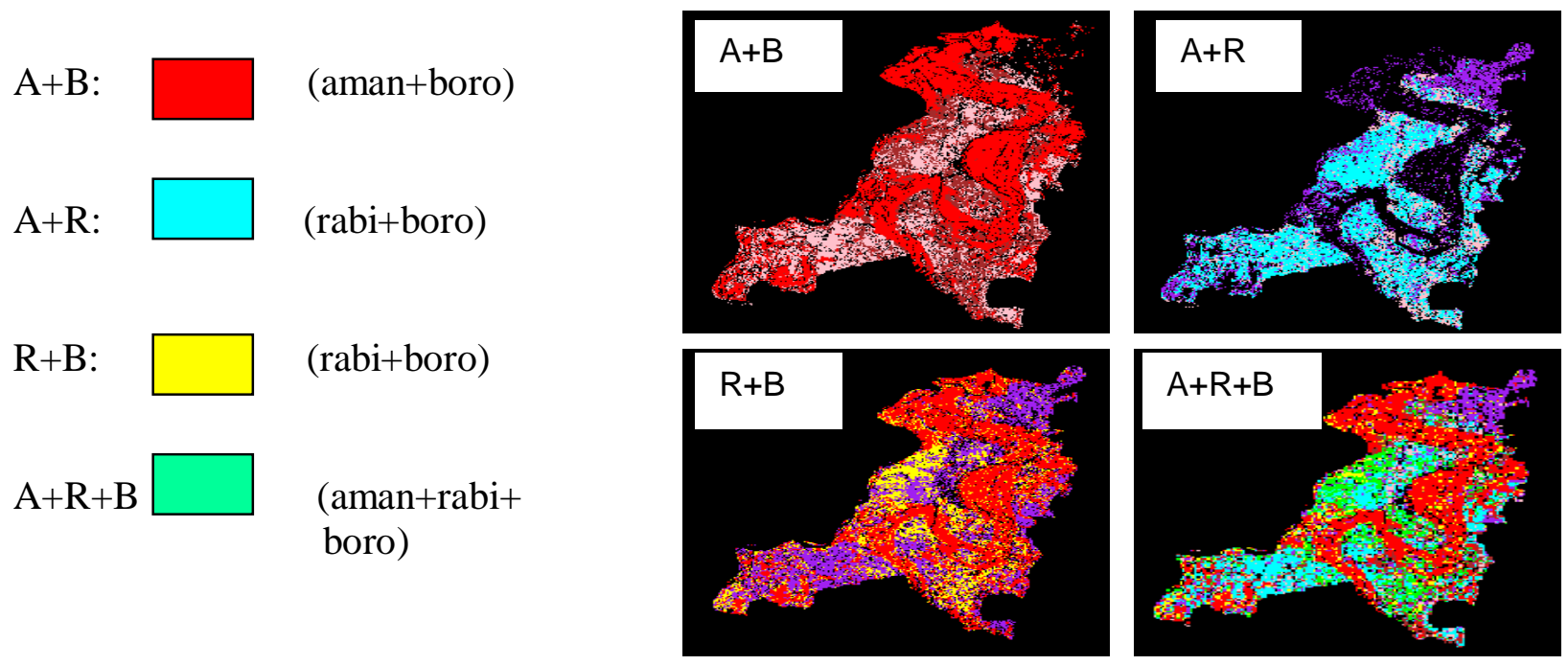

Fig. 7. Identification of the multiple cropping areas.

\section{The land-use map and crop area statistics}

The layer A+R+B (Fig. 7) along with other land-use patterns and the layers obtained from the interpretation of aerial photographs for settlement areas, small water bodies (ponds and ditches), river and canal, high lands were combined and the detailed land-use map had been prepared. The area statistics of the single and multiple cropped areas and other landuse classes are shown in Table 3 and the land-use map of Brahmanbaria is represented with different color codes in Fig. 8. 
Table 3. The area statistics of the landuse classes of Brahmabaria district

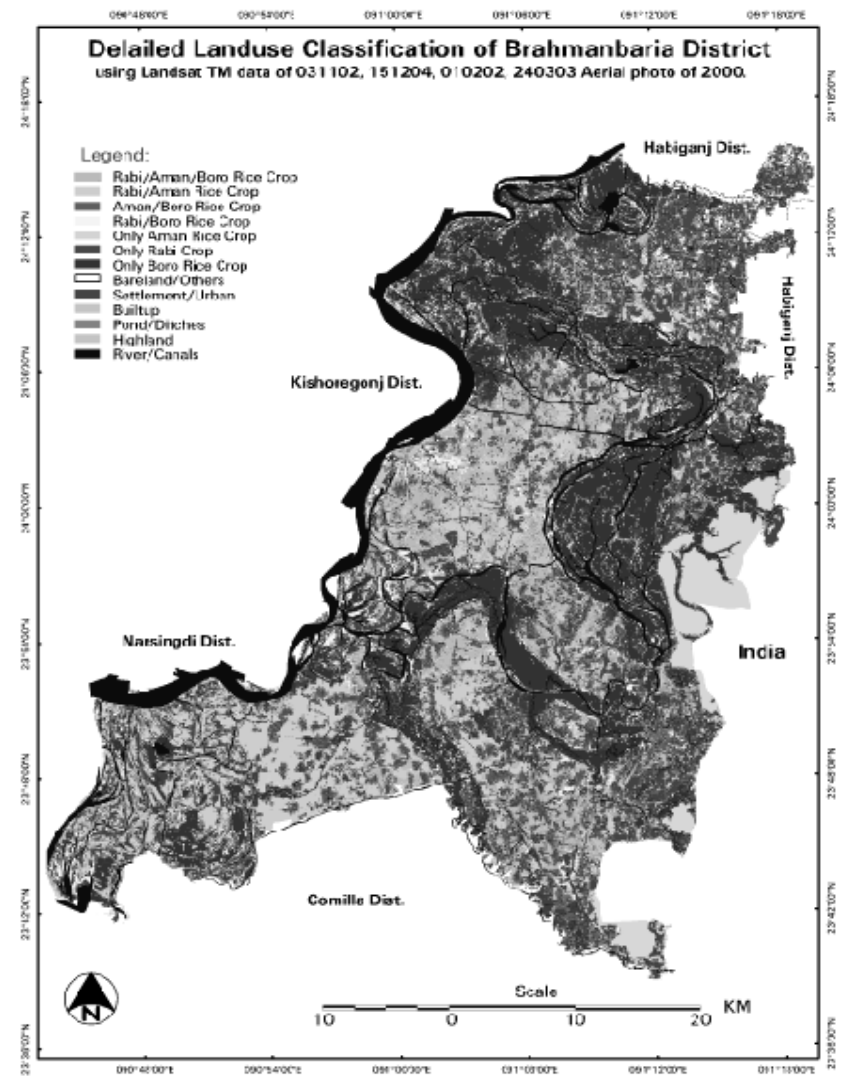

Fig. 8. Detailed land-use classification map of Brahmanbaria district

The statistics showed that the boro coverage accounts for the dominant land-use of the area. The flood plains of the River Titas was covered by boro rice. This was a single crop area as this area remains deeply inundated in the monsoon season and was not suitable for cultivation or plantation of any crops. The total boro rice area occupied 93,000 ha and aman rice area occupied 53,000 ha. This shows that the former is nearly double of the latter. The bare land covers about 7,000 ha. The study area is highly fertile and intensive cropping is practiced over this area with double and triple cropping (Table 3). The rabi crops cover about 61,000 ha. The settlement areas cover more than 21,000 ha which was about $11.4 \%$ of the

\begin{tabular}{|l||l|l|}
\hline Land cover types & Area (ha) & $\%$ Cover \\
\hline Only Rabi & 12180 & $6.4 \%$ \\
\hline Only Boro & 51289 & $27.0 \%$ \\
\hline Rabi/Boro & 11499 & $6.1 \%$ \\
\hline Only Aman & 4383 & $2.3 \%$ \\
\hline Aman/Rabi & 20176 & $10.6 \%$ \\
\hline Aman/Boro & 12639 & $6.7 \%$ \\
\hline Aman/Rabi/Boro & 17560 & $9.2 \%$ \\
\hline Bare land/Others & 6822 & $3.6 \%$ \\
\hline Settlement & 21634 & $11.4 \%$ \\
\hline Builtup & 1638 & $0.9 \%$ \\
\hline Pond/Dishes & 6276 & $3.3 \%$ \\
\hline Highland/Valley & 6887 & $3.6 \%$ \\
\hline River/Canal & 17077 & $9.0 \%$ \\
\hline Total Area & 190061 & $100 \%$ \\
\hline
\end{tabular}

total area. The rivers and canals occupied about 17,000 ha and ponds and ditches 6,300 ha. The highlands occupied about 6,900 ha.

\section{Land-use classification of Akhaura upazila and their correspondence with land types}

The more detail land-use map has been prepared for the Akhaura upazila of the Brahmanbaria district (Fig. 9). The Table 4 contains the statics of the land-use items. The land-use classification of Akhaura upazila has also been investigated against the land-type maps for this upazila (Fig. 10). Table 4 shows that the total area of boro rice was nearly double than that of aman. 


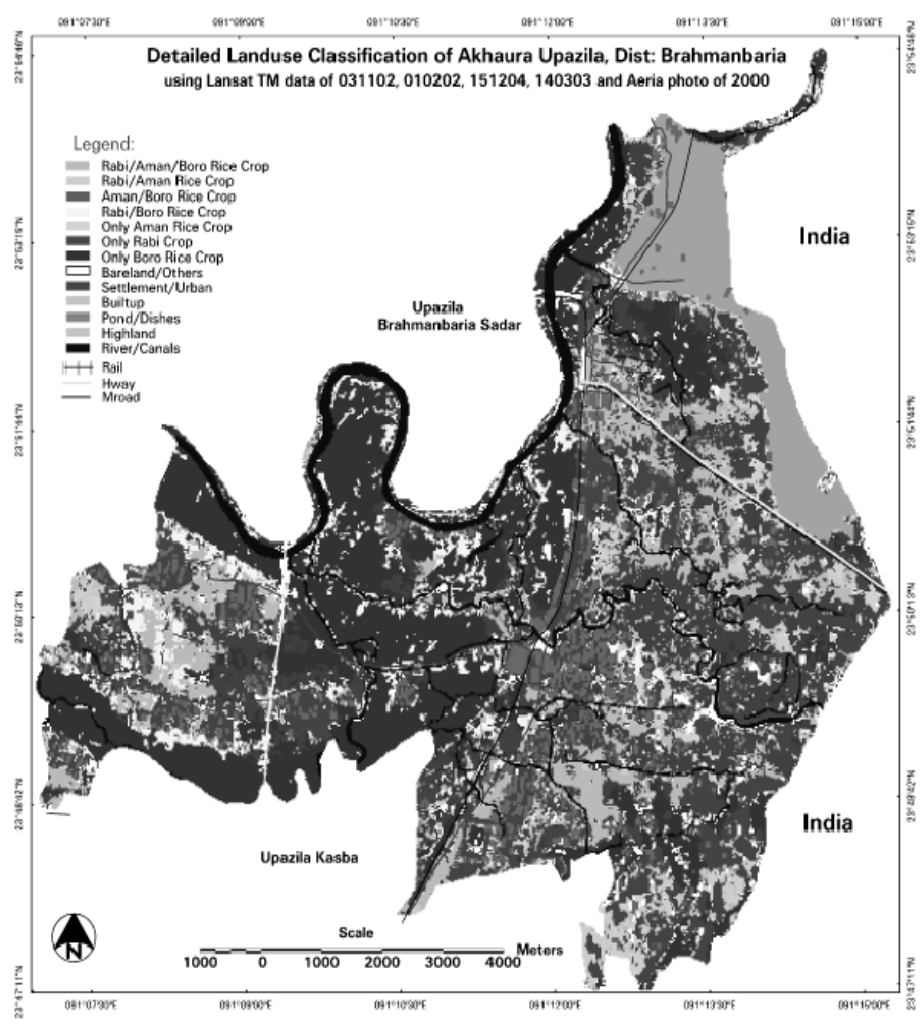

Table 4. The statistics of the detailed landuse of Akhaura upazila

\begin{tabular}{|l||l|l|}
\hline Land cover types & Area(ha) & $\%$ Cover \\
\hline Only Rabi & 170 & $2.0 \%$ \\
\hline Only Boro & 2272 & $26.4 \%$ \\
\hline Rabi/Boro & 461 & $5.4 \%$ \\
\hline Only Aman & 223 & $2.6 \%$ \\
\hline Aman/Rabi & 279 & $3.2 \%$ \\
\hline Aman/Boro & 1306 & $15.2 \%$ \\
\hline Aman/Rabi/Boro & 826 & $9.6 \%$ \\
\hline Highland/Valley & 576 & $6.7 \%$ \\
\hline Builtup & 47 & $0.5 \%$ \\
\hline Settlement & 1102 & $12.8 \%$ \\
\hline Pond/Dishes & 555 & $6.4 \%$ \\
\hline River/Canal & 564 & $6.6 \%$ \\
\hline Roads/Rail & 181 & $2.1 \%$ \\
\hline Others & 43 & $0.5 \%$ \\
\hline Total & 8605 & $100 \%$ \\
\hline
\end{tabular}

Fig. 9. The detail land-use map of Akhaura upazila

The comparison of the landuse pattern with the landtypes shows a good correspondence of the land-use features with the land-types. It is found that the low lands in the flood plains were used for early planted boro. These areas were single cropped where the high lands were used for settlement, aman rice, rabi crops and boro rice. The latest one i.e., boro rice was cultivated over these areas having irrigation facilities. The relatively highlands or higher flood plains were characterized by double and triple crops (aman+rabi+boro, aman+rabi, rabi+boro). These features are also quite clear in the landuse map of Brahmanbaria district as well (Fig. 8). 

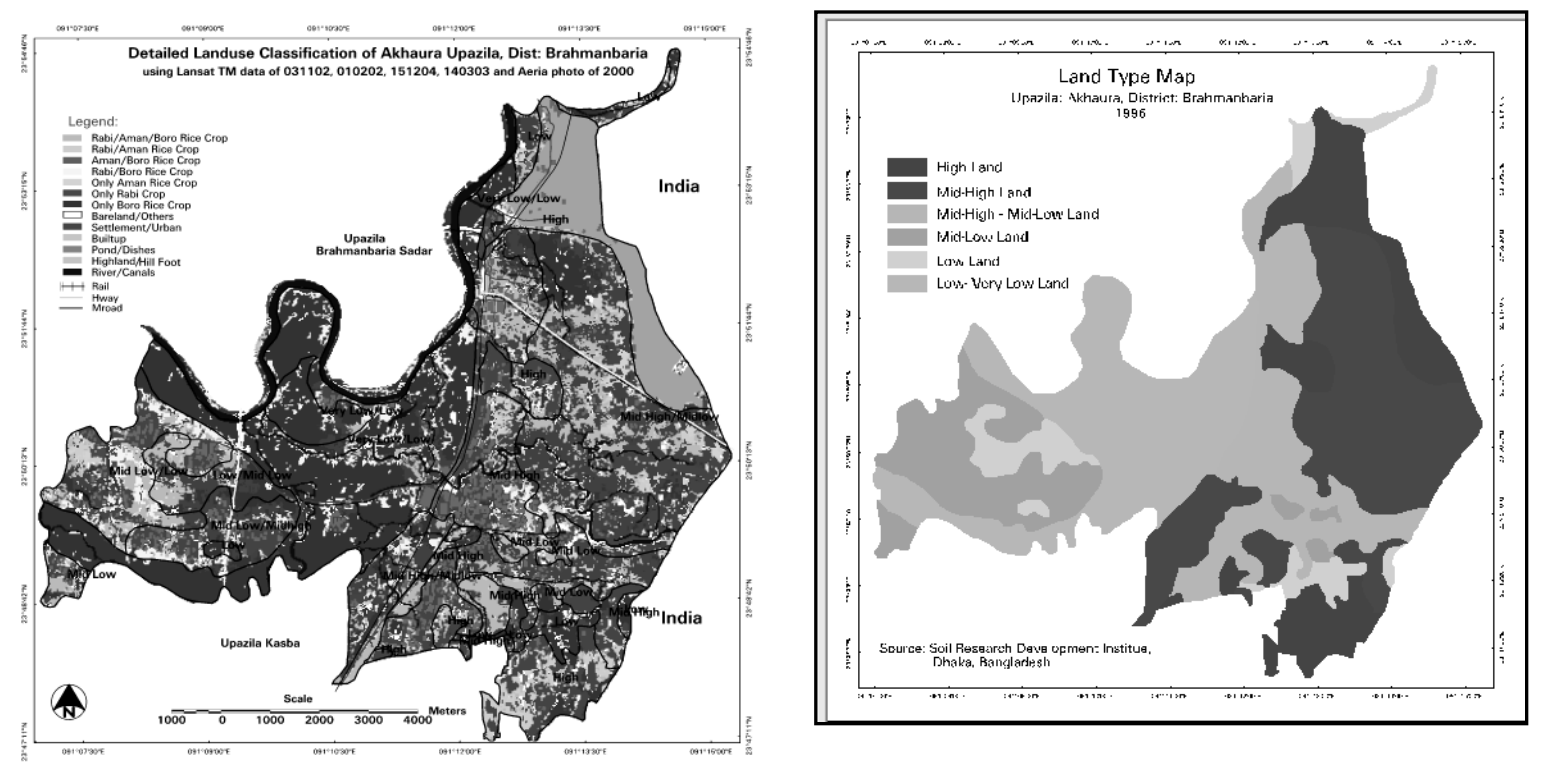

Fig. 10. The land-use map and the land type map (after SRDI, 1996).

\section{Conclusions}

Remote sensing and GIS technology have been effectively utilized in land-use study. The Landsat TM multi-date and multi-spectral imagery have been successfully used for deriving the landuse maps. The multi-spectral signatures extracted from the Landsat TM imagery of the individual dates through selection of features using AOI were used to classify the images covering the major crop seasons.

The incorporation of aerial photographs have given an additional dimension to the work where the high resolution features such as rivers and canals, ponds and ditches, settlement areas, bare soil and the highlands have been interpreted. The satellite imagery interpretation and classification using the spectral signatures of the green crops have been performed and the detail land-use map has been derived.

Further analysis for selected area (Akhaura upazila) against the land-type map shows a good correspondence among the landuse pattern and landtype distribution. Titas River was used for early planted boro rice planting. The relatively higher flood plains were used for aman rice, late planted boro rice and rabi crops. These were used for double and triple cropped area also. The results of the study could provide a good understanding about the landuse of the study area and would support the proper land zoning process for optimal use of land for economic development as well as in preservation of ecology.

\section{References}

Quadir, D. A. and M. Nessa. 1998. Rice Monitoring in Bangladesh using Remote Sensing Technique Proceeding of the Euro-Asia Space Week on Cooperation in Space- 'Where East and West Meet', 23-27 November 1998, Singapore (ESASP 430, February 1999)

Choudhury, A. M., Quadir, D. A., Nessa, M., Parveen, S. and Haque, F. 2002. Study of lwinter crops in Bangladesh using remote sensing and GIS, SPARRSO report on DTW II Project of Bangladesh Agriculture Development Corporation (BADC), Dhaka, Bangladesh. 